\title{
A note on abbreviations
}

In most chapters I have used abbreviations to suggest camera positioning and framings so as to clarify the structure and content of the scenes, or parts of scenes, used as examples. The frame sizes are described in relation to the parts of the body or a familiar scene. I am aware that some of these expressions are more specific than those commonly used in the film and television industries but feel that a more detailed approximation is more useful in giving a clearer impression of the image size being described in the text:

$\begin{array}{ll}\text { ExBCU } & \text { extreme big close-up: eye or mouth } \\ \text { BCU } & \text { big close-up: eyes to mouth } \\ \text { CU } & \text { close-up: face and neck } \\ \text { CS } & \text { close shot: head and shoulders } \\ \text { MCS } & \text { medium close shot: head to hip or thigh level } \\ \text { MS } & \text { medium shot: two to four people, full height } \\ \text { MWS } & \text { medium wide shot: a street crossing } \\ \text { WS } & \text { wide shot: a bowling green } \\ \text { VWS } & \text { very wide shot: a football pitch } \\ \text { ELS } & \text { extreme long shot: a desert }\end{array}$

In the main I have tended to avoid the expression long shot (LS), which can mean WS or VWS, and can also be confused with the amount of time it's held on the screen. I've made an exception to my own rule with ELS, perhaps because a shot revealing this much would have to stay in vision for quite some time as well.

There are a number of other abbreviations and expressions which appear throughout the book and these are explained below:

CAM The camera.

CAM left (or The space immediately to the left of the camera; this might L) or right refer to a character's exit as being oblique and close to the (R) camera. Cf. frame left.

dissolve The gradual appearance of a new scene as the old scene fades into it. 
frame left The left side of the film frame irrespective of the camera or

(or $\mathrm{L}$ ) right $(\mathrm{R})$ position and at right angles to it.

high angle An elevated camera position at least $10 \mathrm{ft}$ above the ground and often considerably more,

low angle A camera position that can be anything from just beneath head height to just above floor level with the camera looking up.

OOV or OOS Out of vision, or out of shot. This usually refers to sections of dialogue that are heard, but not seen to be spoken, because the image on the screen is of someone or something else.

POV Point of view. A shot of a place, person or object, presented in such a way as to suggest that it is being seen by a character in the film. It is usually interposed between looks or glances in the preceding and following shots.

raised angle A camera position above head height but less than a high angle. Cf. high angle.

SRS Shot, reverse-shot. Cutting between two people facing each other, usually in CU or CS with the camera remaining on one side of both characters to cover the angle changes.

2-shot (or 3- This refers to the number of characters framed in the shot. It shot) could be any number but it's seldom used for more than five. 